\title{
AN ANALYSIS OF THE POSITIVE INOTROPIC EFFEGT OF ANAPHYLAXIS WITH POTASSIUM GONTRACTURE IN GUINEA PIG ATRIA, IN CONNECTION WITH THOSE OF INOTROPIG AGENTS
}

\author{
AKIRA UENO, MASAMICHI MATANO AND YOSHIRO NAKAZAWA \\ Department of Pharmacology, Nagasaki University School of Medicine, Nagasaki \\ Received for publication May 28, 1964
}

The anaphylactic manifestation in the atrium isolated from a sensitized guinea pig is an increase in the contractile tension and in the beat rate $(1,2)$. Although the reaction is similar to the response of histamine, serotonin and adrenaline, it has not been blocked by antihistaminics (3) or DCI (4). So it is probable that the reaction occurs as a primary effect of anaphylactic manifestation taking place in cardiac muscle fibers (1). It was also found in our laboratory that the time course of repolarization of the transmembrane action potential of proper atrial fiber of guinea pig is prolonged during anaphylaxis $(5,6)$. Furthermore, records of action potential of specialized fibers in the sinoatrial node during anaphylaxis showed the increased slope of the prepotential without any changes in its height (4). Similar observation of action potential change in intestinal segment during anaphylaxis has also been reported by Katsh and Marshall (7). So the prolongation of action potential duration in muscle fiber seems to be a ubiquitous change occurring in the anaphylactic manifestation.

On the other hand, some results have been presented indicating that the duration of the action potential is one factor determining the contractility: changes in temperature alter both electrical and mechanical activity $(8,9)$, and tension and action potential duration decrease progressively as frequency increased in the rat atrium (9) and the guinea pig atrium (6), and several studies reported a change of comparable magnitude in action potential duration and contractility (10-13). These observations, however, do not imply that change in contractility must be associated with changes in action potential duration: that has also been confirmed in a number of studies (14-16). Therefore, the use of intracellular microelectrode technique to study electrical activity of cardiac muscle fibers has not provided much new information on the relationship between electrical and mechanical responses, and further investigation with different approaches is needed to discuss mechanism of the inotropic effect.

In order to obtain further informations on the mechanism of anaphylactically induced inotropic action it seemed of interest to study the effect on contraction when muscle membrane is depolarized in the definite level. This can be done by studying 
the participation of anaphylactic manifestation on contractures of auricle preparation induced by application of depolarizing potassium chloride solution. However, attitudes of most drugs on the potassium contracture have not been reported with a few exception (17-19). The authors have also studied the effects of various agents having an inotropic action in guinea pig atria on the potassium contracture.

\section{METHODS AND MATERIALS}

About one hundred and fifty left atria taken from exsanguinated guinea pigs were used in the experiment. Immunological sensitization of the guinea pig was carried out by intravenous injection of anti-egg-albumin rabbit serum, having $1 \times 128$ to $1 \times 256$ antibody title $(0.3 \mathrm{ml}$ per $100 \mathrm{~g}$ body weight), 24 hours prior to the experiment.

The left atria suspended in $32-33^{\circ} \mathrm{C}, 15 \mathrm{ml}$ bath, having an aspirating orfice to keep a proper fluid level during replacements of solutions and sintered glass filter at the bottom to provide bubbling mixture of $95 \%$ oxygen and $5 \%$ carbon dioxide.

The tension was recorded by an unbonded strain gage transducer (Shinkoh Communication Co., Ltd.: UL-120-10 or UL-120-50), in connection with either an automatic balancing strain recorder (AS-2) or a dynamic strain amplifier (DS6-P) and direct recording microammeter (Yokogawa Electric Works Co., Ltd.), with $600 \mathrm{mg}$ in initial load. Arrangement of the apparatus was shown in Fig. 1.

Bath solutions used in the experiment were Ringer's solution composed of $\mathrm{NaCl}$ $154 \mathrm{mM}$, KCl $5.6 \mathrm{mM}, \mathrm{CaCl}_{2} 2.2 \mathrm{mM}$, glucose $5.0 \mathrm{mM}, \mathrm{NaHCO}_{3} 5.95 \mathrm{mM}$ per liter, and

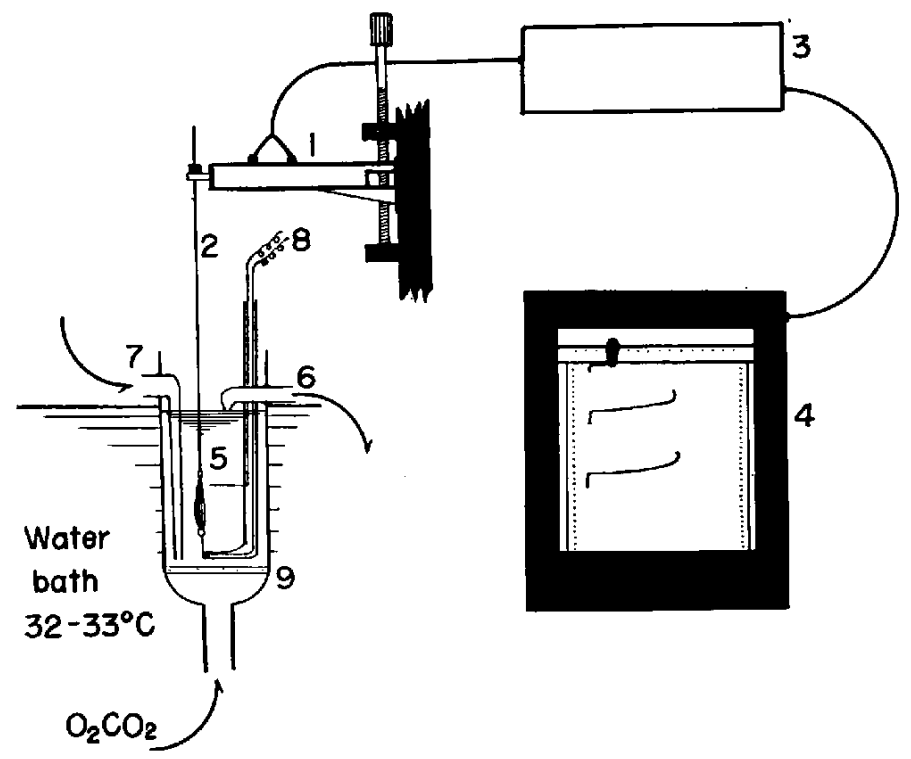

FIG. I. Arrangement of the apparatus.

1 , strain gage; 2 , chromium plating still wire; 3 , strain amplifier;

4 , recorder; 5 , muscle bath; 6 , aspirating orfice ; 7 , inflow tubing;

8 , muscle holder with stimulating electrode; 9 , glass filter. 
a potassium solution composed of $160 \mathrm{~mm}$, glucose $5.0 \mathrm{~mm}, \mathrm{NaHCO}_{3} 5.95 \mathrm{~mm}$ per liter. The solution will be described as the potassium solution in this paper.

The potassium contracture of the atrium was induced by replacing Ringer's solution with the potassium solution by perfusion of $400 \mathrm{ml}$ of the solution through the bath with an excess aspiration which provides to maintain a proper fluid level. After the tension development in the potassium solution was completed, the potassium solution was replaced with Ringer's solution, then the developed tension quickly disappeared, and electric drive of the atrium was begun with rectangular pulses of $5 \mathrm{msec}$ in duration, 120 pulses per minute at supramaximal voltages for a predetermined period of time. The stadium of electrical driving is a reconditioning period following potassium contracture. In order to obtain a reproducible contracture, further precautions described in details in the following chapter were needed.

Observations of the transmembrane potential of the atrium were carried out in some cases during the exposure to the potassium solution by intracellular microelectrode technique. The method is the same as that previously described (5). Used agents and its final concentrations throughout the experiment are as follows: egg albumin (Merck) $20 \mu \mathrm{g} / \mathrm{ml}$, adrenaline-HCl $0.01 \mu \mathrm{g} / \mathrm{ml}$, histamine-HCl $1.0 \mu \mathrm{g} / \mathrm{ml}$, serotonin creatinine sulfate $1.0 \mu \mathrm{g} / \mathrm{ml}$, nicotine sulfate $40 \mu \mathrm{g} / \mathrm{ml}$, caffeine with sodium benzoate $1.0 \mathrm{mg} / \mathrm{ml}$, $\mathrm{BaCl}_{2} \cdot 2 \mathrm{H}_{2} \mathrm{O} 0.532 \mathrm{mg} / \mathrm{ml}, \mathrm{CaCl}_{2} \cdot 2 \mathrm{H}_{2} \mathrm{O} 0.32 \mathrm{mg} / \mathrm{ml}$, acetylcholine chloride $0.01 \mu \mathrm{g} / \mathrm{ml}$.

\section{RESULTS}

1. Normal feature of the potassium contracture

An extremely slow development of tension, a potassium contracture, was seen as the atrium was exposed to the potassium solution (5-10 minutes), after electrically driven in Ringer's solution for a relatively short lperiod of time (10-15 minutes). And the solution was replaced with Ringer's solution when the exposure period was terminated

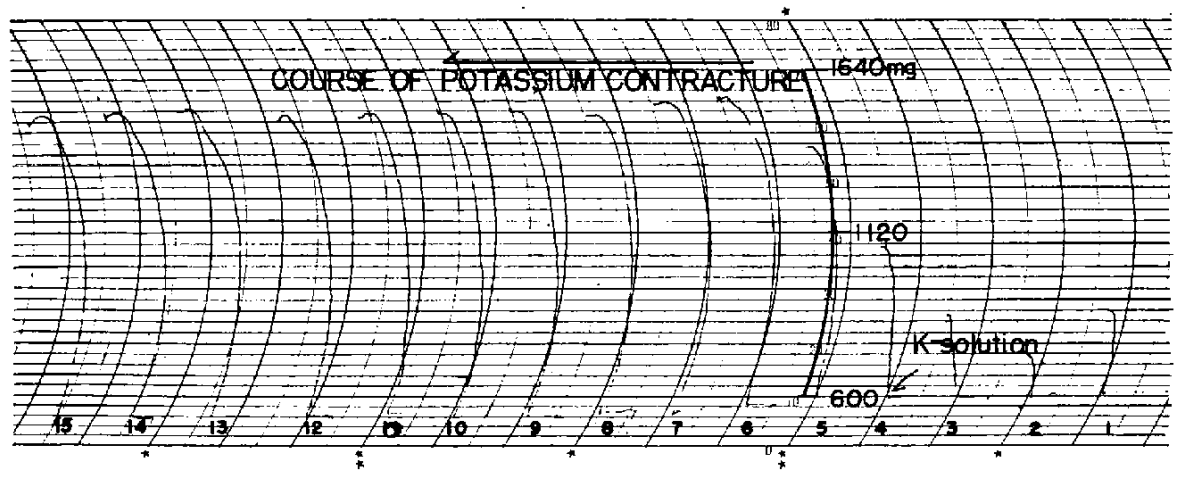

FIG. 2 A. Full record of contractile responses of guinea pig atrium to the potassium solution.

The record was proceeded from right to left. The numbers below the record denote the times of exposure to the potassium solution, and uniform responses were obtained between 8 and 15. See text. 
and driven electrically for 15 minutes (reconditioning interval). And then the next exposure to the potassium solution was repeated in the same manner, and so forth.

In this circumstance, devclopment of the tension was first increased as the exposure was advanced, usually up to 5 or 10 times, and then responded uniformly several times (Fig. 2 A). Fig. 2 B shows a course of a typical contracture in the steady state. Results discussed in this paper are concerned only with the contracture in the steady state unless otherwise stated.

Magnitude of the transmembranc potential of atrial fibers during the exposure to the potassium solution appeared as $-11.4 \mathrm{mV}$ (average of 6 cases) against outer fluid, whereas it appcared as $-90 \mathrm{mV}$ in Ringer's solution.

2. Modification of the potassium contracture due to anaphylactic manifestation and agents which change contractile force

Application of antigen and inotropic agents were carried out in the following four manners: a) adding with the potassium solution, b) in the completed contracture state,

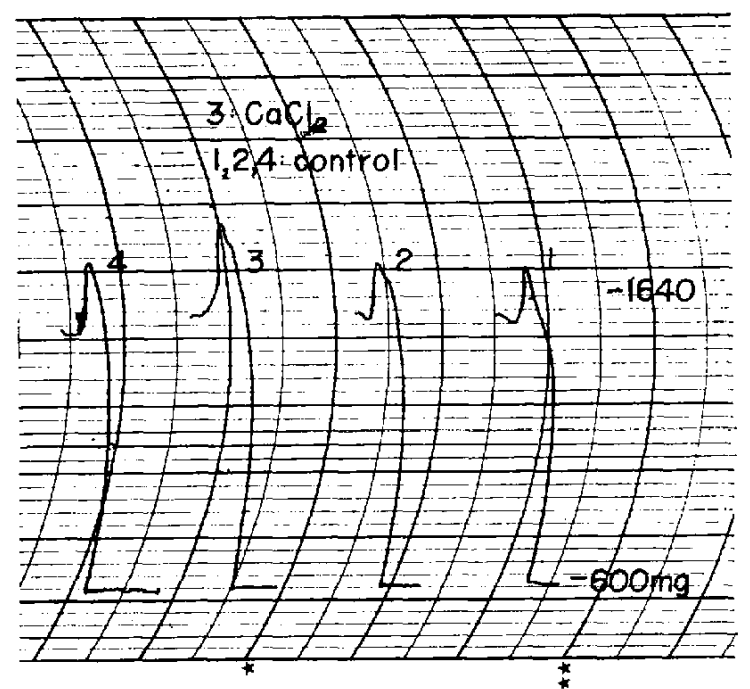

FIG. 3. Enhancing effect of Ca given with the potassium solution on the contracture. 
c) in reconditioning interval in which atria are driven electrically, d) adding with the potassium solution in Ca-depleted state (Figs. 2B, 6).

\section{a. Effects of the specific antigen and agents applied with the potassium solution}

Developed tension of potassium contracture in sensitized atrium was slightly enhanced $(10-20 \%)$ by the potassium solution containing antigen (egg albumin) in a concentration of $2 \mathrm{mg} \%$. But no effect was observed in the normal atria by antigen, and by adrenaline, histamine, serotonin, nicotine and acetylcholine (agents of group A) applied in this manner. While the magnitude of the contracture was enhanced $10-20 \%$ by $\mathrm{BaCl}_{2}$, caffeine and $\mathrm{CaCl}_{2}$ (Fig. 3) (agents of group B).

It is noticeable that caffeine and $\mathrm{BaCl}_{2}$ enhanced the contracture as well as $\mathrm{CaCl}_{2}$ and that there is a distinct difference between the agents of group $A$ and the $B$ in their mode of action on the potassium contracture.

\section{b. Effects of the agents in the depolarized state}

When caffeine was added in the completed potassium contracture state, a near completely depolarized state ( $-11.4 \mathrm{mV}$ against outer fluid), another increase of tension was obtained on the course of the potassium contracture (Fig. 4). And a similar effect was observed by adding of $\mathrm{BaCl}_{2}$ and $\mathrm{CaCl}_{2}$.

But adrenaline, histamine, serotonin, nicotine and acetylcholine did not modify the normal course of the potassium contracture. Antigen application for sensitized atria also showed no effect.

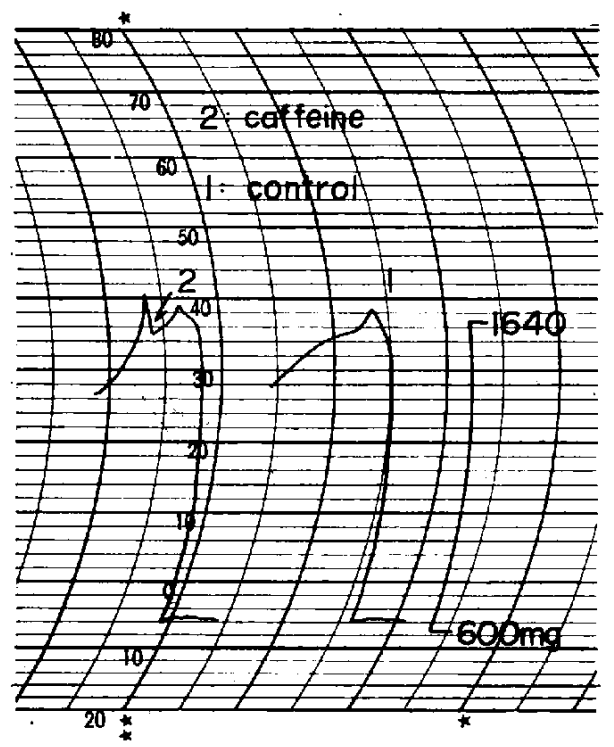

FIG. 4. An increase of tension on the course of the contracture caused by caffeine given in the completed contracture state.

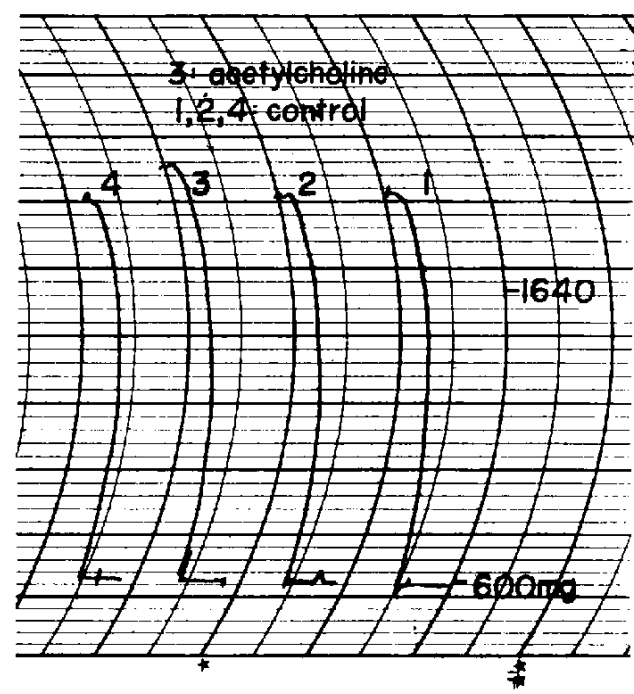

Fis. 5. Effect of acetylcholine given in reconditioning interval on the contracture.

Acetylcholine was added in driven state 3 minutes prior to the potassium exposure in 3 . 


\section{c. Changes of the contracture when agents were given in the reconditioning interval}

The agents were added in two to five minutes prior to the exposure of the potassium solution in the reconditioning interval, in which atria are driven in Ringer's solution, and their influences on followed potassium contracture were observed.

The magnitude of the contracture was slightly increased by adrenaline, histamine, serotonin, nicotine and acetylcholine (Fig. 5). And incrcased 20-30\% by $\mathrm{CaCl}_{2}$, caffeine and $\mathrm{BaCl}_{2}$.

A marked enhancement of the contracture in sensitized atria was also produced by the administration of antigen.

It is significant that every agent enhances the magnitude of the contracture after they are applied in the reconditioning interval in which the excitable membrane has been normally activated by electric stimulation. In other words, repetitive excitations under the presence of the agents of group A produce a factor acting inotropically.

\section{d. Effects of the agents on the contracture in $\mathrm{Ca}$ depleted state}

After the atrium soaked in Ca free Ringer's solution instead of the normal one in the reconditioning interval, it was exposed to the potassium solution several times. The tension development went down and became a state responding uniformly with small contracture (Fig. 6). The condition could be understood as Ca depleted state of the

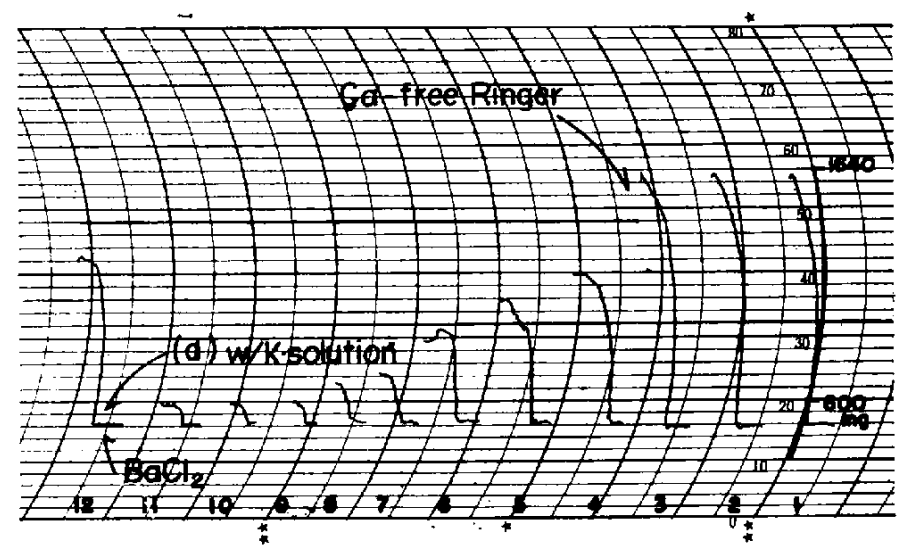

Fic. 6. Action of $\mathrm{Ba}$ on the potassium contracture in $\mathrm{Ca}$ depleted state. 1,2 and 3, normal potassium contracture ; since 4 Ca free Ringer's solution was used instead of normal Ringer's solution in reconditioning interval ; at 12, Ba was administered with the potassium solution.

atrium. No further effect was observed by applying antigen with the potassium solution to a sensitized atrium of this state. And adrenaline, histamine, serotonin, nicotine and acetylcholine with the potassium solution also showed no effect on the contracture, but application of $\mathrm{CaCl}_{2}, \mathrm{BaCl}_{2}$ (Fig. 6) and caffeine in the same manner produced marked contracture as in the normal state. This fact indicates that $\mathrm{Ba}$ and caffeine can substitute the role of $\mathrm{Ca}$ in the contracture of this state. 


\section{DISGUSSION}

The present investigation indicates that positive inotropic effect of anaphylaxis in the potassium contracture of guinea pig atria is recognizable only when antigen was applied with the depolarizing potassium solution and applied in the driven state in Ringer's solution, a period of the reconditioning interval in the series of the potassium contracture. And the other circumstances in the administration of antigen, namely application in completed potassium contracture state (depolarized state), and application with the potassium solution in $\mathrm{Ca}$ depleted state has no influence on the potassium contructure, while adrenaline, serotonin, histamine, nicotine and acetylcholine (agents of group A) increase magnitude of the potassium contracture only when they were added in the driven state prior to the contracture. In contrast, agents of group $\mathrm{B}, \mathrm{Ca}, \mathrm{Ba}$ and caffeine, enhance the potassium contracture without regard to the method of administration, which is especially marked in the Ca depleted state.

Above findings indicate that the mode of inotropic action of anaphylactic manifestation is of somewhat different nature from that of agents mentioned above. Further they also suggest that the prolongation of action potential duration in atria observed during anaphylaxis $(1,5,6)$ may not play a fundamental role in anaphylactically induced force enhancement, because the enhancement of the contracture is observed when antigen is applied with the potassium solution.

It is apparent that mechanism of anaphylactically induced force enhancing effect is not directly concerned with action on contractile mechanism of muscle fiber, since no modification is demonstrated by addition of antigen in the depolarized state and $\mathrm{Ca}$ depleted state.

Contracture enhancing effect of agents of group $\mathrm{A}$ is demonstrable only when their administrations are made in the driven state, i.e. in the reconditioning interval of the contracture. The mechanism of the inotropic action, therefore, may be to alter a certain membrane functioning depending on membrane excitation, that is to say, repeating of membranc excitation under the presence of thesc agents plays a role to enhance the force. Similar mechanism is also considered in anaphylactically induced force enhancement.

On the other hand, $\mathrm{Ca}, \mathrm{Ba}$ and caffeine enhance the potassium contracture irrespective of methods of application. The finding clearly indicates that the mode of inotropic action of the agents of group $B$ is to act directly on contractile mechanism or alternatively to affect the relation between depolarization and contraction. Mode of action of $\mathrm{Ca}$ in this way is already pointed out by Niedergerke (19). Present investigation gives also an evidence that $\mathrm{Ba}$ and caffeine act similarly as $\mathrm{Ca}$, since $\mathrm{Ba}$ and caffeine reproduce the potassium contracture of the atrium in Ca depleted state. There is a probable connection between attitudes of action of these agents in the potassium contracture and the rate of Ca-uptake in guinea pig atria, as previously reported from our laboratory that the agents of group A and anaphylaxis increase Ca-uptake, and Ba 
and caffeine decrease it (1).

From above findings it is probable that anaphylactically induced positive inotropic effect differs from that of $\mathrm{Ba}$ or caffeine and that there may exist a substrate competition between $\mathrm{Ca}$ and $\mathrm{Ba}$ or caffeine in a certain part of the cell membrane.

\section{SUMMARY}

Anaphylactically induced force enhancing effect in the isolated guinea pig atrium was analyzed by its attitude against potassium contracture, and compared with those agents which act inotropically in the guinea pig atrium.

1. Potassium contracture of the guinea pig atrium was induced by the replacement of Ringer's solution with $160 \mathrm{mM} \mathrm{KCl}$ solution. The contracture was reproduced several times. And transmembrane potential of the proper atrial fiber in the potassium solution appeared as $-11.4 \mathrm{mV}$ against the outer fluid.

2. A slight increase in magnitude of the contracture of the sensitized atrium was induced by the administration of antigen with the potassium solution, and marked enhancement in the contracture was evoked when antigen was applied in the driven state prior to the contracture, while the administration in the completed contracture state and Ca-depleted state had no effect.

3. The enhancing effect of adrenaline, histamine, serotonin, nicotine and also of acetylcholine on the contracture was demonstrated only when the agent is added in the driven state few minutes prior to the contracture.

4. Administrations of $\mathrm{Ca}, \mathrm{Ba}$ and caffeine enhanced the magnitude of the contracture without regard to the method of the administration, but this was especially marked in the $\mathrm{Ca}$ depleted state.

\section{REFERENCES}

1) Ueno, A. : Proceedings of the 16th General Assembly of the Japan Medical Congress, Osaka, Vol. 1, 176 (1963) (Japanese)

2) Nakazawa, Y., Sakai, O. AND Kobata, S. : Nishin Igaku 45, 147 (1958) (Japanese)

3) KiHARA, F. : Nagasaki Igaku Z. 34, 1612 (1959) (Japanese)

4) KIDO, M. : Acta med. nagasaki 9, 29 (1964)

5) Ueno, A., Murakami, K. and Nakazawa, Y.: lbid. 8, 41 (1964)

6) Matayoshi, M. : Nagasaki Igaku Z. : 39, 234 (1964) (Japanese)

7) Katsh, S, and Marshall, J.M. : Amer. J. Physiol. 196, 39 (1959)

8) Ueno, A. : Unpublished data

9) Hollander, P.B. And Leyden, M.E. : Circulation Res. 3, 604 (1955)

10) Burgen, A.S.V. And Terroux, K.G. : J. Physiol. 119, 139 (1952)

11) Kleinfeld, M., Greene, H., Stein, E. and Macin, J. : Amer. J. Physiol. 181, 35 (1955)

12) Kleinfeld, M., Stein, E. ANd Myers, S. : Circulation Res. 2, 488 (1954)

13) Webi, J., Leyden, M.E. and Hollander, P.B. : Ibid. 4, 332 (1956)

14) Duddei, J. and Trautwein, W. : Cardiologia 25, 344 (1154)

15) Hoffman, B.F. nNd Bindler, E. : Amer. J. Physiol. 185, 95 (1956) 
16) Trautwein, W. And Duddel, J. : Arch. ges. Physiol. 260, 24 (1954)

17) LUtttgau, H. and Niedergerke, R. : J. Physiol. 143, 486 (1958)

18) Otsuka, M. and Nonomura, Y.: J. Pharmacol. 141, 1 (1963) -

19) Niedergerke, R.: J. Physiol. 134, 584. (1956) 